\title{
A EVOLUÇÃO DA GESTÃO AMBIENTAL NOS MUNÍCIPIOS BRASILEIROS
}

\section{Carina Angélica dos Santos}

Universidade Federal de Sergipe, Campus universitário José Aloísio de Campos São Cristóvão, Sergipe - Brasil

profcarina@gmail.com

\section{Carla Zoaid Alves dos Santos}

Universidade Federal de Sergipe, Campus universitário José Aloísio de Campos São Cristóvão, Sergipe - Brasil

doczoaid@gmail.com

\section{Laura Jane Gomes}

Universidade Federal de Sergipe, Campus universitário José Aloísio de Campos São Cristóvão, Sergipe - Brasil

laurabuturi@gamil.com

\section{Napoleão dos Santos Queiroz}

Universidade Federal de Sergipe, Campus universitário José Aloísio de Campos São Cristóvão, Sergipe - Brasil npqueiroz@yahoo.com.br

Recebido em 08/09/2020. Aprovado em 16/10/2020. DOI: dx.doi.org/10.5380/guaju.v6i2.76399

\section{Resumo}

A gestão ambiental municipal se tornou um dos principais fatores de articulação político-administrativa do desenvolvimento sustentável local. A capacidade dos municípios em instituírem seus Sistemas Municipais de Meio Ambiente SISMUMA tem sido um passo fundamental para a efetividade dessa gestão. No entanto, faz-se necessário um acompanhamento do processo de descentralização da gestão ambiental no Brasil e do modo como os municípios têm operado os seus SISMUMAs. A realização deste trabalho teve como objetivo analisar a evolução da gestão ambiental municipal no Brasil considerando cinco áreas específicas: Estrutura, Legislação, Recursos Humanos, Conselho e Fundo Ambiental, agrupadas por regiões brasileiras. Para isso, utilizou-se como base o banco de dados da Pesquisa de Informações Básicas Municipais - MUNIC, do Instituto Brasileiro de Geografia e Estatística - IBGE, considerando uma série de dados dos anos 2002, 2013 e 2017, este, último ano de publicação dos dados para a área ambiental. Os resultados apontaram que até o ano de 2017 houve um avanço na estrutura ambiental dos municípios brasileiros, principalmente, após a publicação da Lei Complementar 140, de 2011. Observou-se, por exemplo, o aumento do número 
de órgãos ambientais e do quantitativo de pessoal empregado na área, mas ainda existem diferenças quanto à dinâmica de evolução entre as regiões brasileiras, principalmente na Região Nordeste. Apesar da evolução constada até o ano de 2017, recomenda-se a continuidade da pesquisa e ampliação dos fatores que podem influenciar na determinação da capacidade da gestão ambiental dos municípios brasileiros, bem como uma análise quanto às alterações que vêm sendo realizadas na estrutura ambiental brasileira após o ano de 2018, e como estas afetarão a gestão ambiental nos municípios brasileiros.

Palavras-chave: Políticas públicas. Lei Complementar 140. Arranjo Institucional. IBGE.

\title{
The evolution of environmental management in brazilian municipalities
}

\begin{abstract}
Municipal environmental management has gradually become one of the main factors in the political and administrative articulation of local sustainable development. The capacity of the municipalities to establish their Municipal Environmental Systems SISMUMA has been a fundamental step towards the effectiveness of this management. However, it is necessary to monitor the process of decentralizing environmental management in Brazil and the way in which municipalities have operated their SISMUMA's. The purpose of this work was to analyze the evolution of municipal environmental management in Brazil considering five specific areas: Structure, Legislation, Human Resources, Council and Environmental Fund, grouped by Brazilian regions. Thus, the database of the Basic Municipal Information Survey-MUNIC of the Brazilian Institute of Geography and Statistics - IBGE was used as a base, considering a series of data from 2002, 2013 and 2017, the last year of publication of the data for the environmental area. The results showed that until the year 2017 there was an advance in the environmental structure of Brazilian municipalities, mainly after the publication of Complementary Law 140, of 2011. It was observed, for example, the increase in environmental agencies and the number of employees employed in the area, but there are still differences in the dynamics of evolution between the Brazilian regions, mainly in the Northeast region. Despite the evolution observed until the year 2017, it is recommended to continue the research and expand the factors that may influence the determination of the environmental management capacity of Brazilian municipalities, as well as an analysis of the changes that have been made in the environmental structure after the year 2018, and how they will affect environmental management in Brazilian municipalities.
\end{abstract}

Keywords: Public policies. Complementary Law 140. Institutional Arrangement. IBGE. 


\section{Introdução}

A questão ambiental passou a fazer parte do cotidiano dos municípios brasileiros tendo como marco a Constituição Federal de 1988, a qual proporcionou aos municípios maior autonomia para gerir os assuntos de seu interesse e suplementar a Legislação Federal e Estadual quando necessário (BRASIL, 1988). É interessante observar que a Constituição de 1988, claramente, determinou à União, aos Estados, ao Distrito Federal e aos Municípios o dever de proteger o meio ambiente e de combater a poluição, estabelecendo o poder de polícia e de controle dos entes federativos para licenciar, fiscalizar e auditar de forma a garantir um ambiente ecologicamente equilibrado.

O cenário da gestão ambiental municipal no Brasil também está diretamente associado ao histórico da Política Nacional de Meio Ambiente - PNMA (BRASIL, 1981), a qual criou o SISNAMA - Sistema Nacional do Meio Ambiente. Esse sistema é um importante instrumento de fortalecimento institucional que tem como premissa básica a criação de uma estrutura e a formulação de políticas condizentes e próprias para que cada município possa exercer a sua capacidade de gestão ambiental (AVILA; MALHEIROS, 2012).

Ainda dentro desse contexto sobre as normativas que garantem a proteção ambiental após 23 anos da Constituição, com o fito de disciplinar as obrigações advindas do art. 23, inciso VI da Constituição de 1988, a Lei Complementar 140/2011 vem regulamentar as competências dos entes federativos no âmbito da gestão ambiental (BRASIL, 2011). A norma é um marco regulatório fundamental para a instrumentalização da gestão ambiental nos municípios, que além de ratificar o que já tinha ficado claro na data da Promulgação da Constituição de 1988, detalha a competência de cada ente federativo sobre a proteção ambiental.

O ponto que é interessante ao tema é o que se refere ao município: a Lei Complementar 140/2011 estabelece uma estrutura política mais autônoma, na qual fica claro o contexto singular para a municipalidade, detalhado pelas competências inerentes a esse ente federativo. Aliada a essa autonomia surge a necessidade de organização institucional dos municípios para que possam efetivamente assumir todo processo de gestão de forma satisfatória.

Apesar da formalização desse processo ser uma necessidade, ao se avaliar o potencial de gerenciamento e de monitoramento que os municípios devem dispor para implantá-lo 
e para acompanhá-lo, verifica-se a existência de uma série de desafios. Esses desafios vão desde a efetivação do SISNAMA e a sua integração com as instâncias decisórias, até a sua viabilização na esfera municipal, por meio dos Sistemas Municipais do Meio Ambiente SISMUMA (MALHEIROS et al., 2008; FERNANDES et al., 2012; RODRIGUES; FERNANDES, 2012).

E mesmo após quatro décadas da instituição da criação do SISNUMA (BRASIL, 1981) e de todas as iniciativas e dos esforços, a sua efetivação e a sua integração com as instâncias da esfera municipal continuam sendo o principal desafio. Scardua e Bursztyn, em 2003, enfatizaram que nem todos os municípios brasileiros possuíam a mesma habilidade e a mesma facilidade de implantar os instrumentos definidos para a gestão ambiental. Pode-se afirmar que a situação exposta pelos autores continua sendo válida até os dias atuais.

A administração municipal é o nível mais próximo do cidadão e os gestores têm em suas mãos o desafio de influenciar e de proporcionar as mudanças de comportamento necessárias, bem como planejar e executar medidas que acelerem o desenvolvimento sustentável local, promovendo respostas mais rápidas e eficientes em todas as áreas do bem-estar populacional.

A gestão ambiental é, sem dúvida, um processo potencializador dessas questões no momento que se propõe a se preocupar com os mecanismos de regulação e de controle da qualidade ambiental. Pode inclusive auxiliar as estratégias de formulação de políticas públicas voltadas para tecnologias de saúde e de bem-estar da população (PINHO; WEINERT, 2020).

Conhecer e monitorar a qualidade dessa gestão ambiental no âmbito municipal e como ela está sendo operacionalizada é um tema, diretamente, relacionado com as discussões globais sobre o desenvolvimento sustentável, sobretudo ao identificar que a ação local é um fator determinante para o alcance das mudanças pretendidas, logo, os gestores municipais têm em suas mãos o grande desafio de planejar e de executar essas medidas. Portanto, monitorar e examinar como a gestão ambiental vem sendo desenvolvida no país se tornou um dos quesitos para a avaliação do desenvolvimento local.

Como consequência, os municípios devem estabelecer suas políticas e a partir da compreensão das suas dificuldades locais devem definir qual direcionamento devem adotar. No entanto, Azevedo et al. (2007) afirmaram que para promover a descentralização era preciso atrelar esse processo à capacidade institucional, e a administração local ao controle social e ao mecanismo de flexibilização, expectativa essa materializada em 2011. 
Porém, surge o seguinte questionamento: a Lei Complementar 140/2011 contribuiu para a descentralização da gestão ambiental na esfera municipal?

Considerando esse contexto, a realização deste trabalho teve como objetivo analisar a evolução da gestão ambiental municipal no Brasil por meio da Capacidade Institucional Ambiental, considerando cinco áreas com este fim: Estrutura, Legislação, Recursos Humanos, Conselho e Fundo ambiental municipal. Os dados foram agrupados por regiões brasileiras e após isso a mesma análise foi realizada de forma mais detalhada para as capitais do Nordeste brasileiro.

\section{Capacidade institucional ambiental dos municípios brasileiros}

\section{Metodologia}

A pesquisa aplicada foi descritiva, baseada na aplicação de métodos quantitativos de coleta de informações em bases estatísticas verificadas a partir dos dados de cada tema apresentado (GIL, 2010; RICHARDSON, 2011).

A coleta de dados foi realizada na base de informações do IBGE, especificamente o MUNIC - Municípios das Regiões do Brasil. Inicialmente, realizou-se uma análise da série histórica dos dados disponibilizados, de modo que ao avaliar esse repositório identificouse que a sumarização de informações referentes à gestão ambiental ocorreu de forma padronizada para os anos de 2002, 2013 e 2017, ou seja, nesses três anos a coleta foi realizada de forma semelhante, por isso foram selecionados como os anos de apoio desta pesquisa e até o momento desta publicação os dados de anos posteriores $(2018,2019$ e 2020) não haviam sido publicados pelo IBGE.

Para analisar os dados coletados e determinar a Capacidade Institucional Ambiental utilizou-se como base os estudos de De Carlo (2006), Leme (2016) e Pacheco et al. (2016), que também analisaram a estrutura da gestão ambiental nos municípios brasileiros, considerando os dados do MUNIC/IBGE até o ano de 2013.

De Carlo (2006), em seu estudo, procurou identificar os fatores que contribuem para melhor comprometimento com a gestão ambiental no âmbito municipal, analisando os desafios e as contradições da descentralização por meio de uma pesquisa quantitativa, levando em conta critérios da questão ambiental a partir de dados do MUNIC/IBGE (2002) e 
do MUNIC/IBGE-Gestão Pública (2004), aplicando método estatístico para melhor retratar o grau de comprometimento dos municípios com a referida gestão.

Leme (2016) procurou identificar a capacidade instalada nas prefeituras para promover a gestão ambiental local nos itens de Estrutura de meio ambiente, de Pessoal, de Conselho, de Recursos Financeiros e de Legislação. No estudo de Pacheco et al. (2016), os autores discutiram sobre a evolução da capacidade instalada dos municípios brasileiros no desenvolvimento de estratégias que subsidiam as políticas públicas em gestão ambiental conforme os dados apresentados pelo MUNIC, bem como realizaram uma análise temporal, quantitativa e descritiva, com base nos anos de 2002 e 2013 acerca da evolução referente à estrutura administrativa, aos Recursos Humanos, à legislação específica, à existência de conselho e do fundo ambiental e à implementação de ações da Agenda 21.

Assim, baseado nos estudos citados, os dados coletados foram estratificados quanto: à Estruturação do órgão gestor; à Legislação ambiental específica; ao Conselho ambiental; ao Fundo ambiental e aos Recursos Humanos, considerando a série histórica dos anos de 2002, 2013 e 2017 (Figura 1).

Figura 1 - Chave de avaliação da capacidade institucional ambiental para os municípios brasileiros

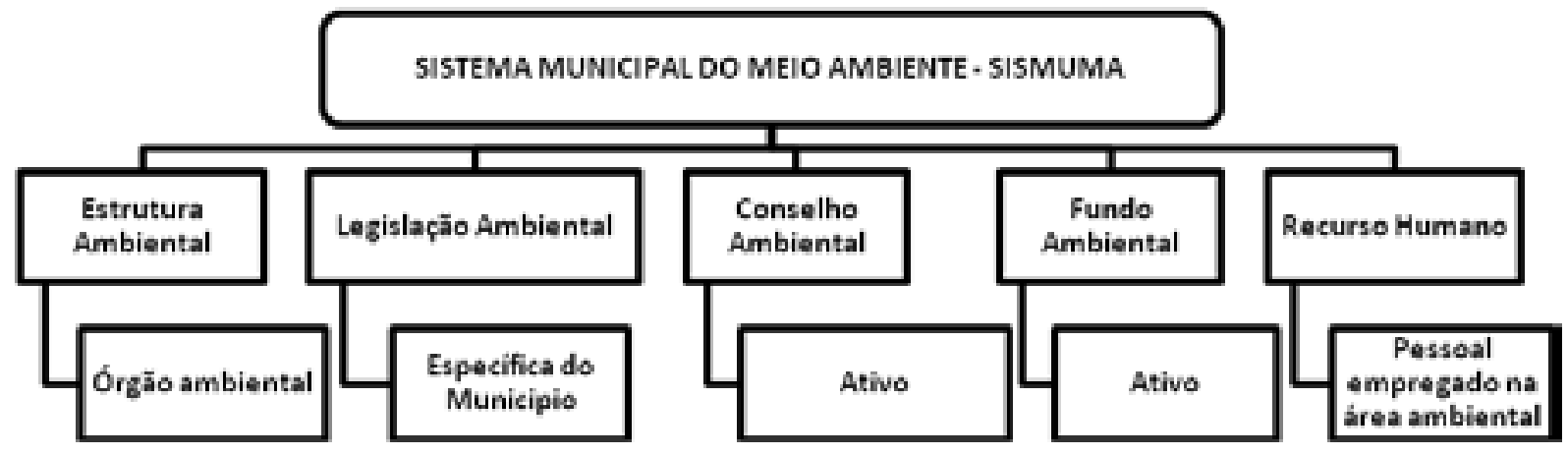

Fonte: Os Autores (2019).

A Estrutura Ambiental foi caracterizada pela checagem da ausência ou da existência de um setor ambiental no município. No caso de existente, foi verificado se o setor de gestão municipal era: 1. Exclusivo de meio ambiente ou 2. Integrado a algum outro órgão da estrutura municipal.

A Legislação Ambiental é um instrumento de regulação essencial para revelar a Capacidade Institucional Ambiental do município. Para isso, analisou-se a existência 
de legislações ambientais próprias do município e as temáticas de interesse local que regulamentam essas legislações.

Quanto ao Conselho Municipal, verificou-se a existência deste, sua atividade e a realização de pelo menos uma reunião por ano. Já em relação ao Fundo Municipal do Meio Ambiente, além de verificar a existência deste, observou-se também se possuía conselho gestor próprio.

Os Recursos Humanos foram analisados quanto ao quantitativo de pessoal ocupado na área de meio ambiente e ao regime de contratação desses Recursos Humanos: se concursados, se de cargos de confiança e se estagiários.

Após a análise do panorama geral dos municípios brasileiros por região, observouse que a Região Nordeste apresentou os valores mais baixos dos percentuais gerais para os temas analisados. Com isso, realizou-se um recorte da região e as mesmas temáticas foram consideradas de forma mais detalhada para as capitais, com o acréscimo de mais um item de análise para o Fundo do Meio Ambiente: se este estava ativo. Foram totalizadas seis áreas de avaliação, sendo que cada item foi analisado de forma detalhada por capital para a composição da nota por meio de uma análise binária: quando a estrutura analisada estava presente, foi atribuída a nota "1" ao tema; quando a estrutura analisada estava ausente, foi atribuída a nota "0" ao tema.

Conforme a classificação do Arranjo da Capacidade Institucional, adaptada de Leme (2016), as capitais foram classificadas conforme uma escala de notas de 0 a 6: quanto maior a nota, maior a capacidade encontrada. Após o preenchimento das notas ( 0 ou 1 ), realizouse o somatório para ranquear as capitais do Nordeste. As capitais, nas quais o somatório pontuasse 0, foram classificadas como "sem arranjo para gestão"; aquelas com pontuação de 1 a 4 foram consideradas como "arranjo intermediário"; e aquelas com pontuação de 5 a 6 foram classificadas como "arranjo consolidado".

Os resultados para todos esses temas foram sistematizados em planilha Excel, organizados e apresentados em tabelas e gráficos. 


\section{Resultados e discussão}

\section{A estrutura ambiental dos municípios}

A efetivação das políticas ambientais depende de uma boa estrutura e o Órgão Municipal de Meio Ambiente (OMMA) é a peça fundamental desse sistema. São atribuições do OMMA planejar, promover, coordenar, fiscalizar e executar a política municipal de meio ambiente, conjuntamente com os demais órgãos municipais, objetivando criar condições para o desenvolvimento sustentá $\neg$ vel do município. A análise detalhada dessa questão foi caracterizada pelo tipo de estrutura existente no município: exclusiva, quando existe uma Secretaria do Meio Ambiente; não exclusiva, quando a secretaria existe, porém, associada com outras temáticas, ou quando corresponde a apenas um departamento ou setor; e outros tipos, quando é um órgão da administração indireta, a exemplo dos institutos e empresas públicas (Tabela 1).

Observou-se que a instituição de um órgão ambiental exclusivo ainda não é considerada uma prioridade. O número de órgãos ambientais integrados a outros temas é maior e quando somado à terceira categoria, que corresponde a outros tipos, esse número é muito maior. Sendo que, no último ano de análise, 2017, apresenta-se um valor geral para o Brasil de $24,96 \%$ dos municípios com órgãos exclusivos, para um valor de $68,36 \%$ dos municípios com estruturas integradas e/ou subordinadas.

Tabela 1 - Evolução da estrutura ambiental brasileira avaliada pelas regiões para os anos base da coleta IBGE/ MUNIC: 2002, 2013 e 2017

\begin{tabular}{|c|c|c|c|c|c|c|c|c|c|c|c|c|c|}
\hline \multicolumn{2}{|c|}{$\begin{array}{c}\text { Total de } \\
\text { municípios }\end{array}$} & \multicolumn{3}{c|}{$\begin{array}{c}\text { Municípios com } \\
\text { estrutura ambiental } \\
\text { (\%) }\end{array}$} & \multicolumn{3}{|c|}{$\begin{array}{c}\text { Presença do órgão } \\
\text { ambiental exclusivo } \\
\text { (\%) }\end{array}$} & $\begin{array}{c}\text { Presença do órgão } \\
\text { ambiental não } \\
\text { exclusivo (\%) }\end{array}$ & \multicolumn{3}{c|}{$\begin{array}{c}\text { Outros tipos de } \\
\text { órgãos }\end{array}$} \\
\hline & & $\mathbf{2 0 0 2}$ & $\mathbf{2 0 1 3}$ & $\mathbf{2 0 1 7}$ & $\mathbf{2 0 0 2}$ & $\mathbf{2 0 1 3}$ & $\mathbf{2 0 1 7}$ & $\mathbf{2 0 0 2}$ & $\mathbf{2 0 1 3}$ & $\mathbf{2 0 1 7}$ & $\mathbf{2 0 0 2}$ & $\mathbf{2 0 1 3}$ & $\mathbf{2 0 1 7}$ \\
\hline BR & $\mathbf{5 5 6 0}$ & $\mathbf{6 8 , 0}$ & $\mathbf{9 0 , 0}$ & $\mathbf{9 3 , 4}$ & & $\mathbf{3 0 , 1}$ & $\mathbf{2 4 , 7}$ & $\mathbf{2 5 , 6}$ & $\mathbf{5 1 , 2}$ & $\mathbf{5 2 , 7}$ & & $\mathbf{1 8 , 7}$ & $\mathbf{1 5 , 6}$ \\
\hline NE & 1792 & 60,0 & 85,2 & 98,2 & $*$ & 26,4 & 20,7 & 21,9 & 56,6 & 58,5 & $*$ & 17 & 11,9 \\
\hline SUD & 1668 & 63,7 & 89 & 90,8 & $*$ & 32,9 & 27,3 & 20,3 & 45,3 & 47,06 & $*$ & 21,8 & 16,4 \\
\hline NO & 449 & 65,5 & 98 & 93,2 & $*$ & 54,0 & 49,11 & 31,6 & 37,4 & 40,4 & $*$ & 7,6 & 8,66 \\
\hline CE & 463 & 78,4 & 92,3 & 96,3 & $*$ & 43,3 & 30,8 & 38,0 & 39,7 & 50,1 & $*$ & 17 & 15,4 \\
\hline SUL & 1188 & 82,1 & 95 & 97,0 & $*$ & 17,1 & 16,3 & 31,7 & 61,2 & 57,7 & $*$ & 21,7 & 23,0 \\
\hline
\end{tabular}

Fonte: Os Autores a partir dos dados do IBGE/MUNIC 2002-2017 (2019).

Nota: A coleta da informação não foi estratificada para as regiões no ano 2000, tal como ocorreu para 2013 e 2017. 
Ao analisar por região, como pode ser observado na Tabela 1, os maiores percentuais de municípios com secretarias exclusivas estão nas Regiões Norte (49,11\%) e Centro-Oeste (30,84\%). O maior percentual de secretarias em conjuntos com outras políticas concentrase nas Regiões Nordeste (58,53\%) e Sul (57,77\%). A unidade da federação que não possuía estrutura particular em 2017 representa 6,59\%. Em 2002 esse valor correspondia a 49\%, demonstrando um significativo aumento de secretarias exclusivas nesses últimos 15 anos.

Leme (2016), em seu estudo, também verificou que as regiões que apresentam os menores percentuais de municípios com estruturas para a gestão ambiental são Nordeste e Sudeste, onde se apontam as regiões com maiores números de municípios. A autora afirma que não existe um tipo ideal de estrutura administrativa e que a maior parte dos municípios tem o desafio de lidar com a gestão ambiental em conjunto com outras políticas.

\section{Legislação Municipal Ambiental Específica}

A série histórica desse instrumento revela que desde 2002, 42,5\% dos municípios possuíam alguma legislação ambiental especial, em 2013 observou-se um aumento para 65,5\% e em 2017 correspondeu a 67\% dos municípios. Ao observar por região, no último ano de análise (2017) a Região Sul apresentou o maior percentual de municípios: 82,5\%; e a Região Nordeste apresentou o menor percentual: 51,4\% dos municípios com essa legislação (Figura 2).

Figura 2 - Proporção (\%) de municípios por região que apresentaram publicação de legislação ambiental específica: evolução para os anos base da coleta IBGE/MUNIC: 2002, 2013 e 2017

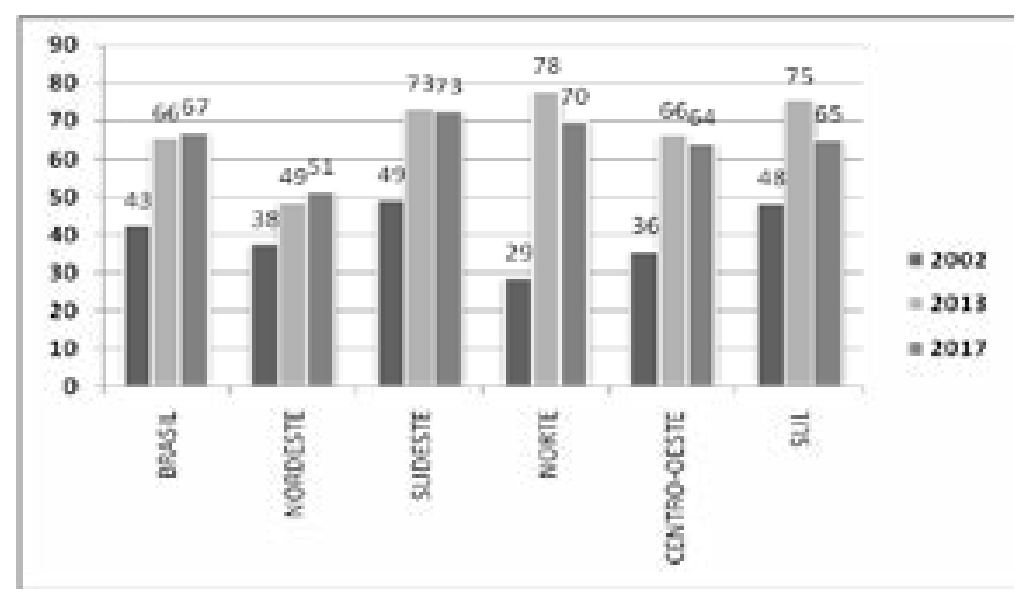

Fonte: Os Autores (2019). 
A publicação de leis delimitadas por áreas peculiares tem uma influência direta na qualidade e no potencial de atuação dos agentes ambientais, principalmente quanto aos dois principais instrumentos ambientais definidos na Política Nacional do Meio Ambiente: Licenciamento e Fiscalização.

Considerando o último ano de coleta do MUNIC, 2017, para este estudo, analisou-se quais as temáticas ambientais estavam mais presentes nos instrumentos de gestão ambiental. Esse tipo de análise foi realizado somente para a coleta de 2017. O tema saneamento básico foi identificado com o maior percentual de publicações: $47,1 \%$; seguido de coleta seletiva de resíduos sólidos: 41,9\%; de área ou zona de proteção: 32,2\%; de poluição do ar: 24,31\%; de floresta, de fauna silvestre e de proteção à biodiversidade: 20,16\%; de permissão de atividades extrativas minerais: $18,67 \%$; de destino das embalagens utilizadas em agrotóxicos: 15,10\%; de gestão de bacias hidrográficas: 14,60\%; e de adaptação e mitigação de mudança do clima: apenas $4,40 \%$.

Há, também, um valor importante a ser observado: 33\% dos municípios não apresentaram nenhuma legislação própria. A legislação específica municipal tem uma importância crucial para o desenvolvimento. Possivelmente, esse número deve ser representado por municípios menores, que nem mesmo são obrigados a elaborarem Plano Diretor, conforme disposto no estatuto da cidade. Em 2017, cerca de $2 / 3$ dos municípios $(67,0 \%)$ tinham legislação especial para tratar da questão ambiental ou algum instrumento de gestão (MUNIC, 2017).

\section{Conselho Municipal de Meio Ambiente (CMMA) e Fundo Municipal Ambiental (FMMA)}

A criação dos CMMA apresentou um salto, de modo que em 2002 apenas 26,1\% dos municípios possuíam Conselhos Ativos; em 2013 esse número foi de 51,6\%; e em 2017 observou-se 74,14\%. A existência de um conselho ativo pontua o item participação comunitária na gestão municipal, a qual na teoria deve contribuir para a melhor gerência dos recursos, diminuindo, assim, os impactos negativos das atividades humanas sobre o meio ambiente (IBGE, 2015).

Os FMMA correspondem a uma forma de captação de receita singular. Criado por lei, os recursos financeiros que compõem o seu orçamento devem, necessariamente, ser vinculados às ações de desenvolvimento das Políticas Ambientais dos municípios.

Observou-se que a institucionalização dos FMMAs foi ampliada, observando-se um 
aumento de 10\% entre os anos de 2001 a 2012, e em 2017 o aumento foi de 50,3\%. Em 2017, uma outra característica observada para os fundos foi se possuíam conselho gestor próprio ou se o gestor era o CMMA ou similar. Nessa análise, 59,55\% possuíam os CMMA ou similar como gestor do fundo e apenas $8,15 \%$ possuíam conselho gestor próprio para o fundo (Figura 3).

Figura 3 - Característica dos fundo municipais do meio ambiente quanto à forma de gestão, Brasil, regiões 2017

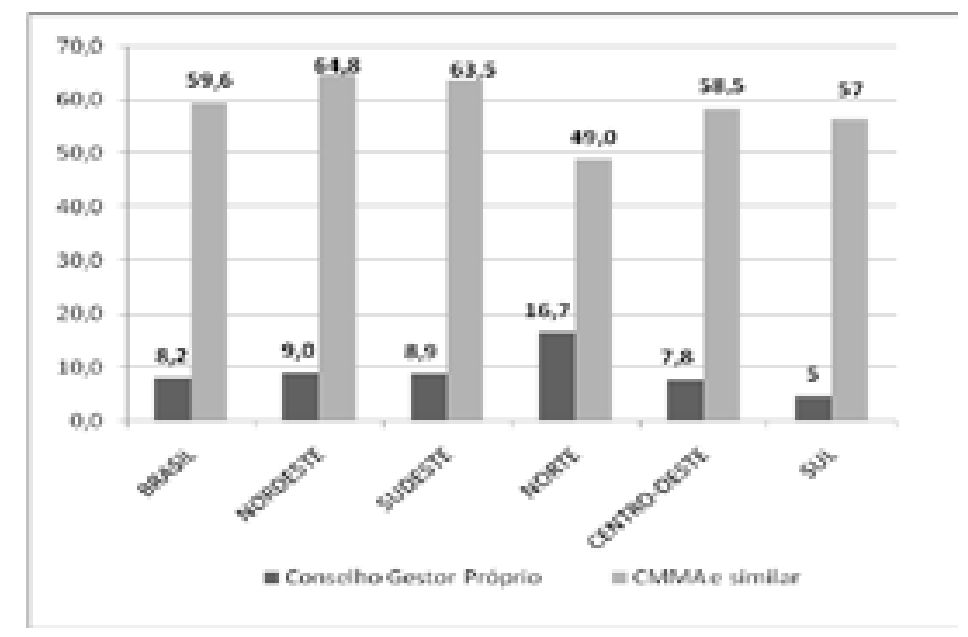

Fonte: Os Autores (2019).

\section{Recursos Humanos na Gestão Ambiental}

Otema Recursos Humanos foi coletado de uma forma diferente das demais temáticas. A classificação feita em 2002 não diferenciava o tipo de vínculo, apenas apresentava o total de pessoal de nível superior ou médio empregado na área ambiental, que correspondia a 31.098 pessoas. As edições seguintes do MUNIC realizaram a coleta de forma estratificada por tipo de vínculo, como representado na Tabela 2. Os Recursos Humanos foram categorizados em: estatutário, celetistas, comissionado e outros (que correspondem a outros tipos de contratação sem vínculo permanente e estagiários). Em 2013, houve um incremento de 32\% de pessoal, principalmente de comissionados, de estagiários e sem vínculo (Tabela 2). 
Tabela 2 - Pessoal ocupado na área ambiental nos municípios brasileiros. proporção por regiões para o ano de 2017 com base na coleta IBGE/MUNIC: 2002, 2013 e 2017

\begin{tabular}{|c|c|c|c|c|c|c|c|c|c|c|c|}
\hline \multicolumn{4}{|c|}{$\begin{array}{c}\text { Pessoal ocupado na área de } \\
\text { meio ambiente }\end{array}$} & \multicolumn{8}{c|}{ \% Regime de contração de pessoal } \\
\cline { 5 - 13 } & \% Estatutário & \multicolumn{2}{c|}{ \% CLT } & \multicolumn{2}{c|}{ \% Comissionado } & \multicolumn{2}{c|}{ \% Outros } \\
\hline & $\mathbf{2 0 0 2}$ & $\mathbf{2 0 1 3}$ & $\mathbf{2 0 1 7}$ & $\mathbf{2 0 1 3}$ & $\mathbf{2 0 1 7}$ & $\mathbf{2 0 1 3}$ & $\mathbf{2 0 1 7}$ & $\mathbf{2 0 1 3}$ & $\mathbf{2 0 1 7}$ & $\mathbf{2 0 1 3}$ & $\mathbf{2 0 1 7}$ \\
\hline BR & $\mathbf{3 1 . 0 9 8}$ & $\mathbf{6 1 . 2 9 5}$ & $\mathbf{5 7 . 5 4 8}$ & $\mathbf{4 5 , 5}$ & $\mathbf{5 0 , 8}$ & $\mathbf{8 , 0}$ & $\mathbf{8 , 2}$ & $\mathbf{2 1 , 1}$ & $\mathbf{2 2 , 9}$ & $\mathbf{2 5 , 3}$ & $\mathbf{1 8 , 1}$ \\
\hline NO & 2526 & $*$ & 6.621 & $* *$ & 42,6 & $* *$ & 2,3 & $* *$ & 26,1 & $* *$ & 29,1 \\
\hline NE & 5866 & $*$ & 13.117 & $* *$ & 38,8 & $* *$ & 4,6 & $* *$ & 34,1 & $* *$ & 22,4 \\
\hline SU & 13547 & $*$ & 23.628 & $* *$ & 52 & $* *$ & 14,3 & $* *$ & 17,6 & $* *$ & 16,1 \\
\hline SUL & 7318 & $*$ & 9.760 & $* *$ & 65,5 & $* *$ & 5,2 & $* *$ & 17 & $* *$ & 12,13 \\
\hline CO & 1841 & $*$ & 4.422 & $* *$ & 58,6 & $* *$ & 1,8 & $* *$ & 26,5 & $* *$ & 13 \\
\hline
\end{tabular}

Fonte: Os Autores a partir dos dados do IBGE/MUNIC 2002, 2013 e 2017 (2019). Nota: * Dado não estratificado por região. ** Dado não coletado por tipo de contratação para a região.

Em 2017, ao observar as unidades da federação em geral, 50,8\% são estatutários, $22,9 \%$ comissionados, $18,1 \%$ outros tipos de contratação. Das regiões do Brasil, os maiores dados de Recursos Humanos estão distribuídos em 65,60\% estatutário na Região Sul, 14,3\% são celetistas no Sudeste, 34,1\% comissionados na Região Nordeste e 29,1\% sem vínculo permanente na Região Norte. Nota-se que houve um crescimento de contingente de funcionários para atender essa área. De 2002 para 2013, o quadro de Recursos Humanos dobrou e em 2017 aumentou em torno de 5\%, mas é importante observar o tipo de contratação, pois é necessário pensar em capacitação permanente de Recursos Humanos para dar continuidade nas atividades ligadas ao planejamento, ao controle, à fiscalização e à execução das ações ambientais.

\section{Capacidade institucional da Gestão Ambiental Municipal para as capitais do Nordeste}

Após a análise macro do panorama brasileiro, foi realizado um recorte para as capitais da Região Nordeste, obtendo-se os resultados apresentados a seguir.

Quanto à estrutura ambiental das capitais nordestinas, verificou-se que em 2002 os municípios de Maceió e de João Pessoa possuíam secretarias próprias; os municípios de Fortaleza, de Natal, de Recife e de Salvador tinham Secretarias do Meio Ambiente ligadas a outras secretarias. Em 2013, a secretaria exclusiva aparece nos municípios de Maceió, de Recife, de João Pessoa, de São Luís e de Aracaju (a última capital do Brasil a criar o seu órgão ambiental). Em 2017, só continuaram exclusivas as secretarias das capitais de São Luís, de João Pessoa e de Aracaju (Tabela 3). 
Tabela 3 - Estrutura ambiental das capitais nordestinas com base na coleta IBGE/MUNIC 2002, 2013 e 2017

\begin{tabular}{|c|c|c|c|c|c|c|c|}
\hline $\begin{array}{c}\text { Capitais do } \\
\text { Nordeste }\end{array}$ & Estrutura ambiental & \multicolumn{3}{|c|}{$\begin{array}{c}\text { Com órgão ambiental } \\
\text { exclusivo (s/n) }\end{array}$} & \multicolumn{2}{c|}{$\begin{array}{c}\text { Com órgão ambiental não } \\
\text { exclusivo ou associado (s/n) }\end{array}$} \\
\cline { 2 - 9 } & Ano de criação & $\mathbf{2 0 0 2}$ & $\mathbf{2 0 1 3}$ & $\mathbf{2 0 1 7}$ & $\mathbf{2 0 0 2}$ & $\mathbf{2 0 1 3}$ & $\mathbf{2 0 1 7}$ \\
\hline Maceió & 1991 & $\mathrm{~S}$ & $\mathrm{~S}$ & $\mathrm{~N}$ & $\mathrm{~N}$ & $\mathrm{~N}$ & $\mathrm{~S}$ \\
\hline Fortaleza & 1992 & $\mathrm{~N}$ & $\mathrm{~N}$ & $\mathrm{~N}$ & $\mathrm{~S}$ & $\mathrm{~S}$ & $\mathrm{~S}$ \\
\hline Natal & 1992 & $\mathrm{~N}$ & $\mathrm{~N}$ & $\mathrm{~N}$ & $\mathrm{~S}$ & $\mathrm{~S}$ & $\mathrm{~S}$ \\
\hline Recife & 1996 & $\mathrm{~N}$ & $\mathrm{~S}$ & $\mathrm{~N}$ & $\mathrm{~S}$ & $\mathrm{~N}$ & $\mathrm{~S}$ \\
\hline Salvador & 1996 & $\mathrm{~N}$ & $\mathrm{~N}$ & $\mathrm{~N}$ & $\mathrm{~S}$ & $\mathrm{~S}$ & $\mathrm{~S}$ \\
\hline João Pessoa & 2002 & $\mathrm{~S}$ & $\mathrm{~S}$ & $\mathrm{~S}$ & $\mathrm{~N}$ & $\mathrm{~N}$ & $\mathrm{~N}$ \\
\hline São Luis & 2007 & $\mathrm{~N}$ & $\mathrm{~S}$ & $\mathrm{~S}$ & $\mathrm{~S}$ & $\mathrm{~N}$ & $\mathrm{~N}$ \\
\hline Teresina & 2008 & $\mathrm{~N}$ & $\mathrm{~N}$ & $\mathrm{~N}$ & $\mathrm{~S}$ & $\mathrm{~S}$ & $\mathrm{~S}$ \\
\hline Aracaju & 2013 & $\mathrm{~N}$ & $\mathrm{~S}$ & $\mathrm{~S}$ & $\mathrm{~S}$ & $\mathrm{~N}$ & $\mathrm{~N}$ \\
\hline
\end{tabular}

Fonte: Os Autores a partir dos dados do IBGE/MUNIC 2002, 2013 e 2017 (2019).

Um detalhe importante a observar foi o ano de criação das secretarias, o que denota algumas particularidades como Maceió, pois apesar de ter sido a primeira a ser criada no Nordeste, não possui uma secretaria especial do meio ambiente, transformando o seu órgão em departamento em 2017. Em Fortaleza, Natal, Recife e Salvador, embora criadas entre 1992 e 1996, desde a sua criação estão associadas a outras políticas setoriais. Dessa forma, só mantém exclusividade desde a sua criação a secretaria de João Pessoa, mostrando que apesar das mudanças de governo permanece com uma área prioritária para tratar das questões ambientais. Em Aracaju e em São Luís observa-se uma evolução, uma vez que os departamentos foram transformados em secretarias voltadas ao meio ambiente, mantendose essa estrutura até o momento.

O avanço na publicação de legislação ambiental municipal específica é notório: na análise do ano 2002, somente Fortaleza não a possuía; nas demais capitais, o assunto estava inserido como um capítulo ou artigo da Lei Orgânica (Aracaju, Recife, João Pessoa, Teresina, São Luís e Salvador); no Plano Diretor (Natal, Recife, João Pessoa e Salvador); no plano de desenvolvimento urbano (Teresina e Salvador); no plano diretor de resíduos sólidos (Natal e Salvador); no plano diretor de drenagem urbana, zoneamento ecológico econômico regional (Teresina e Salvador); e no código ambiental (Maceió, Natal, Recife, João Pessoa e Teresina). Em 2013, o quadro se repetiu semelhante ao de 2002, e em 2017 o quadro equalizou-se com todas as capitais nordestinas possuindo a referida legislação nos mais diversos temas.

Quanto aos conselhos municipais, em 2002 o único município sem conselho foi 
o de São Luís. Ao avaliar 2013 e 2107, algumas distorções foram verificadas: em 2013, foi informado que não existiam conselhos em João Pessoa e em Recife, mas em 2017, o ano de criação desses órgãos, foram registrados para 2002 e para 1992, respectivamente. Em 2017, todas as capitais possuíam esse instrumento, sendo 6 paritários e 3 com representação governamental.

Os FMMA são um dos últimos instrumentos a ser regulamentados nos municípios, de modo que a série histórica analisada mostra que em 2002 apenas Maceió e Fortaleza possuíam fundo; em 2013, Natal, Salvador, Teresina e Aracaju criaram os seus; e em 2017 todas as capitais já haviam criado os seus FMMA. Nas cidades de Fortaleza, de João Pessoa e de Aracaju os fundos possuem um conselho gestor próprio. É interessante observar o quanto a Capacidade Institucional Ambiental - CIA avançou após 2013.

Quanto aos Recursos Humanos, observou-se o aumento no número de pessoas empregadas nos órgãos ambientais dessas capitais do ano 2013 para 2017, sendo os municípios que tiveram os maiores aumentos: Maceió (123\%); Teresina (57,14\%); Recife (43,06\%); e Aracaju (40,43\%).

Após identificar e quantificar as características de cada capital, realizou-se a disposição da pontuação atingida, sendo cada cidade distribuída por tema analisado, no qual: para os itens Estrutura, Legislação, existência de Conselho e Fundo Municipal, todas as capitais obtiveram nota "1"; no quesito reunião do conselho, Recife, João Pessoa, Natal e São Luís obtiveram nota"1"; a capital Teresina obteve nota 0,6. Maceió e Fortaleza obtiveram nota "0,5" e Salvador e Aracaju não pontuaram porque não disponibilizaram informações sobre a frequência de reuniões.

Logo após foi feito o somatório dos resultados das capitais que apresentaram melhor nível de organização para a gestão ambiental, sendo João Pessoa, Natal, Recife e São Luís as que possuem um arranjo consolidado para a gestão. Salvador não informou a frequência de reunião do conselho, por isso a nota decaiu. No entanto, Salvador se encontra com arranjo intermediário para lidar com as questões ambientais, isso por não ter informações sobre a quantidade de reuniões realizadas pelo conselho e por não ter respondido se em 2016, ano anterior à pesquisa, utilizou recurso do fundo municipal (Figura 4). Entende-se, dessa forma, que não só um arranjo consolidado garante a efetividade da gestão, como também se deve conhecer as ações ambientais que cada capital está realizando para atuar de forma sólida. 
Figura 4 - Ranking de consolidação da capacidade institucional das capitais do nordeste

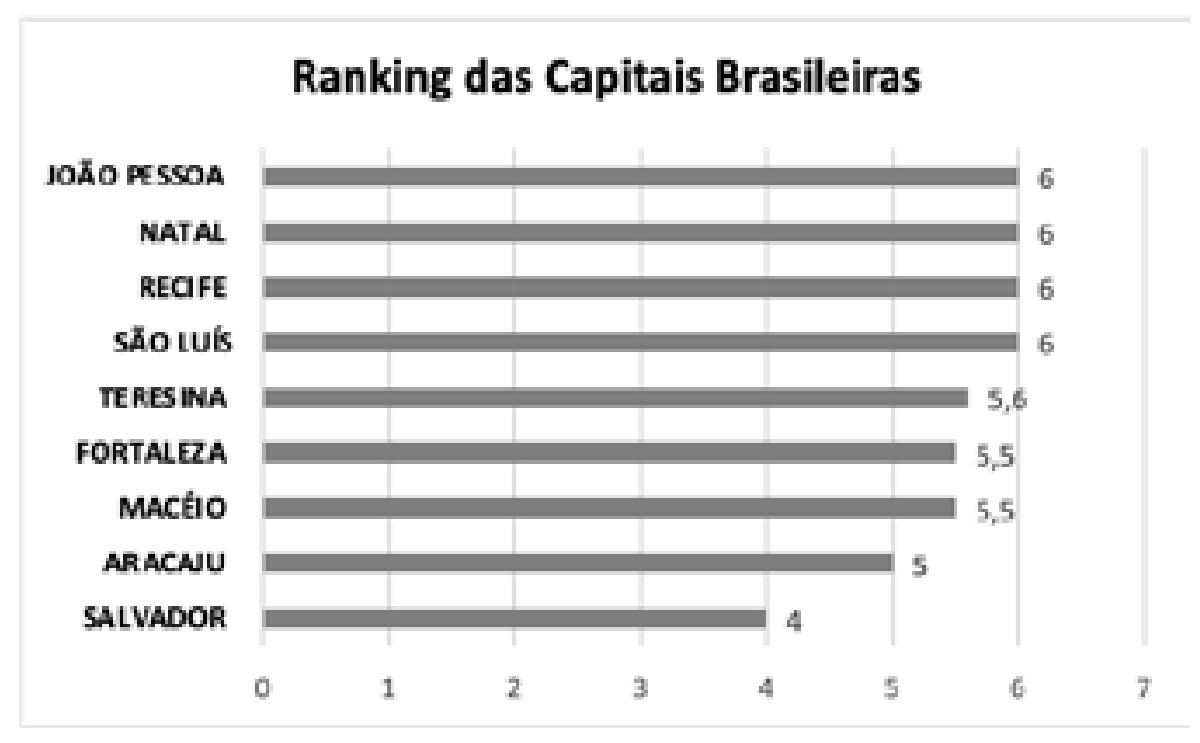

Fonte: Os Autores a partir dos dados do IBGE/MUNIC 2017 (2019).

\section{Considerações gerais sobre a capacidade institucional da gestão ambiental municipal brasileira}

Diante dos dados expostos, observa-se que a estrutura ambiental, certamente, representa um ponto fundamental para a operacionalização da capacidade de gestão, sendo que no Brasil essa estrutura foi caracterizada, principalmente, pelo aumento no número setores específicos para tratar da temática ambiental nos municípios. No entanto, é importante ressaltar que a existência de um órgão público que trate sobre o meio ambiente no município por si só não qualifica a sua Capacidade Institucional de gestão; é preciso articular os demais temas aqui estudados como questões essenciais para operacionalizar todo o SISNUMA.

O Funcionamento da estrutura ambiental apresenta duas importantes relações com dois temas analisados: a legislação específica existente e o quadro de pessoal (Recursos Humanos). A legislação é um recurso que sistematiza a atuação do agente de meio ambiente quanto às questões locais. Além disso, é fundamental que o município possua em seu quadro técnico profissionais habilitados para operar todo esse segmento.

Os resultados avaliados demonstraram um aumento do pessoal atuando na área ambiental e a análise estratificada por tipo de contratação permitiu avaliar o percentual 
de servidores de caráter permanente que estão sendo empregados na área. Esse fator é importante para o processo de continuidade das políticas públicas que são implementadas. Além da importância do aumento de pessoal empregado na área, é interessante a avaliação da capacitação técnica desses servidores. Assim, pergunta-se: Qual é o nível de capacitação que esses servidores possuem na área ambiental? É um questionamento interessante que pode ser incluído na coleta dos próximos MUNIC.

O governo federal, desde 2005, vem desenvolvendo o Programa Nacional de Capacitação (PNC) para gestores ambientais municipais, o qual procura impulsionar positivamente a gerência ambiental compartilhada. Foi criado com intuito de capacitar gestores locais para melhor gerenciar as ações ambientais, bem como para fortalecer o SISNAMA e as estruturas políticas no contexto federativo, consolidando a gestão ambiental compartilhada em parceria com os governos estaduais. Desde a sua implementação, de 2006 a 2012, foram beneficiados 1.688 municípios de forma presencial, capacitando 7.642 pessoas (gestores municipais, funcionários das prefeituras, técnicos das câmaras de vereadores e conselheiros) (MMA, 2020).

A participação social também é uma questão relevante para a capacidade de gestão ambiental. Atualmente, não se concebe qualquer forma de gestão que não considere o planejamento participativo e a população como integrante desse processo, pois são elas que serão afetadas pelos efeitos que as políticas públicas produzem na sociedade. $O$ aumento no número de CMMA foi constatado na análise dos dados e é uma conquista importante. No entanto, é preciso investigar de forma mais especial o modo de participação da sociedade nesses conselhos e como estes estão sendo compostos.

Em 2019, a participação social por meio de conselhos federais foi reduzida no Brasil com a publicação do Decreto Federal no 9.759, de 2019 (BRASIL, 2019). O mesmo aconteceu com o CONAMA - Conselho Nacional do Meio Ambiente, que foi regulamentado por uma normativa instituída em 1990 (Decreto Federal no 99.274), mas que agora, com o recente Decreto Federal n 9.806, de 2019, passou de uma representação composta por 96 conselheiros para um número de 23 membros. A redução das cadeiras dos representantes da sociedade civil foi de 22 representantes para 04 (BRASIL, 2019). É preciso monitorar se nos próximos anos esse efeito exercerá influência sobre os conselhos municipais, observando se o significativo aumento de CMMA ativos, analisados entre os anos de 2002 até 2017, sofrerão reduções ou manter-se-ão constantes, bem como as formas de composição e de participação dessas entidades. 
Os recursos financeiros empreendidos na gestão ambiental também são uma ferramenta importante para o processo de operacionalização e consolidação do SISNUMA. Nesse sentido, os fundos municipais ambientais exercem um papel de destaque ao agregarem como principais fontes de recursos as taxas ambientais, oriundas das multas ambientais, dos licenciamentos e das compensações ambientais, podendo contar com receitas oriundas do próprio orçamento municipal ou do recebimento de doações. A criação dos fundos é um aspecto importante para a capacidade de gestão, pois por meio destes o município pode veicular os recursos financeiros arrecadados dentro de si para a implementação de política municipais ambientais, operando, assim, o seu SISNAMA.

Os municípios brasileiros apresentaram um importante aumento na criação dos seus FMMA, no entanto, muitas cidades ainda não possuem essa ferramenta, cerca de $49 \%$ delas. Outro fator negativo apontado nos resultados é o baixo percentual de FMMAs que possuem conselho gestor próprio, uma característica importante para o gerenciamento das receitas, pois permite avaliar de forma mais participativa se as ações e os projetos que estão sendo propostos pelo executivo são prioritários e se realmente atenderão as demandas da sociedade quanto à aplicação dos recursos arrecadados nas políticas ambientais do município.

Os FMMAs têm uma característica importante para a capacidade institucional da gestão, principalmente, quando os municípios instituem uma lei própria de criação desses fundos e decretam um conselho gestor próprio, pois vincular recursos de multas e de taxas ambientais à receita geral do município pode dificultar o acesso do valor integral da arrecadação somente para a área ambiental.

Por exemplo: em Recife, dos recursos arrecadados provenientes das taxas de licenciamento ambiental e de multas, 60\% é destinado à estruturação e à manutenção da Secretaria do Meio Ambiente, 30\% é reservado para projetos e ações ambientais da própria secretaria e $10 \%$ é destinado para o financiamento de projetos propostos pela sociedade civil (RECIFE, 2019).

Na capital Fortaleza, o Fundo Municipal de Defesa do Meio Ambiente (FUNDEMA) tem como objetivos desenvolver programas de educação ambiental, recuperar ambiente degradado e preservar as áreas de interesse ecológico (FORTALEZA, 2019).

É importante destacar que o Brasil obteve um salto significativo em sua gestão ambiental municipal para os itens analisados nesta pesquisa até o ano de 2017. No entanto, é 
importante ressaltar que após 2018 ocorreram alterações na estrutura da política ambiental brasileira e conforme Ferrante e Fearnside (2019), essas modificações trouxeram prejuízos e retrocessos para questão ambiental no país.

Portanto, é importante que esse monitoramento seja continuado nos anos subsequentes. Certamente, análises futuras poderão quantificar os possíveis impactos que essas alterações podem provocar na gestão ambiental municipal. Pode-se destacar como pontos mais críticos das alterações observadas nos últimos anos: redução da representatividade social do principal conselho ambiental do país, o CONAMA (BRASIL, 2019); migração de pautas ambientais importantes da pasta do Ministério do Meio Ambiente, como a gestão de florestas e de águas, para outras pastas nas quais a questão ambiental não é o foco central, como o Ministério da Agricultura e o Ministério do Desenvolvimento Regional (BRASIL, 2019); propositura de projetos de leis que flexibilizam e alteram as regras do licenciamento ambiental brasileiro (BRASIL, 2018), ferindo os princípios e as diretrizes estabelecidos na própria Política Nacional do Meio Ambiente, dentre outros.

As mudanças observadas na estrutura da política ambiental brasileira nos últimos anos, principalmente 2018 e 2019, podem impactar a evolução da gestão ambiental nos municípios e esses efeitos precisam ser monitorados, verificando se após 2017 houve consequências para a estrutura dessa gestão.

O último relatório da Pesquisa de Informações Básicas Municipais - MUNIC, publicado para o ano de 2018 (IBGE), não analisou a área ambiental. Espera-se que os dados continuem sendo coletados e disponibilizados pelo IBGE, para que futuras análises possam ser realizadas de forma contínua e padronizada.

\section{Conclusão}

Osmunicípios brasileiros na última década assumiram o seu papel de ordenara gestão ambiental em seus territórios de forma mais robusta, intensificando a operacionalização para descentralizar a gestão ambiental no país, principalmente após a publicação da Lei Complementar 140, em 2011.

Até o ano de 2017 os resultados analisados demonstram que houve um avanço da melhoria da estrutura de gestão ambiental dos municípios de modo considerável após 
2013. As mudanças foram refletidas, principalmente, na criação de órgãos específicos para lidar com a questão ambiental e no aumento de Recursos Humanos empregados na área. Observou-se também um salto significativo na implantação dos sistemas, criação de legislação própria, instituição de novos CMMAs e de FMMAs.

Apesar dos avanços constatados até o ano da última análise do MUNIC, em 2017, é importante destacar que as recentes alterações que a política ambiental brasileira vem sofrendo, após 2018, podem impactar esses resultados de forma negativa. Por isso, recomenda-se como proposta para estudos futuros a continuidade de acompanhamento dos dados publicados no MUNIC/IBGE, podendo-se, inclusive, ampliar a pesquisa, considerando fatores como tamanho, região, localização, PIB, classificação da cidade (rural ou urbano) e demais características peculiares de cada município ou mesmo por região, a fim de verificar como esses fatores influenciam na determinação da capacidade de gestão ambiental dos municípios brasileiros.

Destaca-se também a importância do preenchimento de todas as informações pelos gestores dos municípios durante o período da coleta do MUNIC/IBGE, pois foi observado durante a análise dos dados que a falta do preenchimento prejudicou a avaliação e a pontuação da cidade quanto à sua evolução, como foi o caso da cidade de Salvador - BA.

\section{Referências}

ÁVILA, R. D.; MALHEIROS, T. F. O Sistema Municipal de Meio Ambiente no Brasil: avanços e desafios. Revista Saúde Soc. São Paulo, v. 21, supl. 3, p. 33-47, 2012.

AZEVEDO, A.; PASQUIS, R.; BURSZTYN, M. A reforma do Estado, a emergência da descentralização e as políticas ambientais. Revista do serviço público, Brasília, v. 58, n. 1, p. 37-55, jan./mar. 2007.

BRASIL. Constituição Federal. 1988. Disponível em: http://www.planalto.gov.br. Acesso em: 05 set. 2020.

BRASIL. Lei n 6.938, de 31 de agosto de 1981. Dispõe sobre a Política Nacional do Meio Ambiente, seus fins e mecanismos de formulação e aplicação, e dá outras providências. Disponível em: http://www.planalto.gov. br/ccivil_03/LEIS/L6938.htm. Acesso em: 05 set. 2020.

BRASIL. Decreto no 99.274, de 6 de junho de 1990. Regulamenta a Lei no 6.902, de 27 de abril de 1981, e a Lei n 6.938, de 31 de agosto de 1981, que dispõem, respectivamente, sobre a criação de Estações Ecológicas e Áreas de Proteção Ambiental e sobre a Política Nacional do Meio Ambiente, e dá outras providências. Disponível em: http://www.planalto.gov.br/ccivil_03/decreto/Antigos/D99274.htm. Acesso em: 05 set. 2020.

BRASIL. Ministério do Meio Ambiente. Programa Nacional de Capacitação de Gestores Ambientais Municipais. Caderno de Formação: como estruturar o sistema municipal de meio ambiente. Brasília, 2006. v. 2. 
BRASIL. Lei Complementar no 140, de 8 de dezembro de 2011. Dispõe sobre cooperação entre a União, os Estados, o Distrito Federal e os Municípios nas ações administrativas. Disponível em: http://www.planalto.gov. br/ccivil_03/leis/lcp/Lcp140.htm. Acesso em: 02 out. 2018.

BRASIL. Os desafios da Implementação dos Sistemas Municipais de Meio Ambiente. Ministério do Meio Ambiente: Ministério Público do Estado da Bahia. Brasília, DF: MMA; Salvador, BA: MPBA, 2018.

BRASIL. Projeto de Lei do Senado no 168 de 2018. Ementa: Regulamenta o licenciamento ambiental previsto no inciso IV do $\S 1^{\circ}$ do art. 225 da Constituição Federal e dispõe sobre a avaliação ambiental estratégica. Disponível em: https://www25.senado.leg.br/web/atividade/materias/-/materia/132865. Acesso em: 01 nov. 2020.

BRASIL. Decreto n' 9.759, de 11 de abril de 2019. Extingue e estabelece diretrizes, regras e limitações para colegiados da administração pública federal. Disponível em: http://www.planalto.gov.br/ccivil_03/_Ato20192022/2019/Decreto/D9759.htm. Acesso em: 05 set. 2020.

BRASIL. Decreto n 9.806, de 28 de maio de 2019. Altera o Decreto n 99.274, de 6 de junho de 1990, para dispor sobre a composição e o funcionamento do Conselho Nacional do Meio Ambiente - Conama. Disponível em: http://www.planalto.gov.br/ccivil_03/_Ato2019-2022/2019/Decreto/D9759.htm. Acesso em: 05 set. 2020.

BRASIL. Estrutura Organizacional do Ministério da Agricultura (Organograma). 2019. Disponível em: https://www.gov.br/agricultura/pt-br/acesso-a-informacao/institucional/estrutura-organizacional. Acesso em: 01 nov. 2020.

BURSZTYN, Maria A. A.; BURSZTYN, Marcel. Gestão Ambiental no Brasil: arcabouço institucional e instrumentos. In: NASCIMENTO, Elimar P.; VIANNA, João N. Economia, meio ambiente e comunicação. Rio: Garamond, 2006.

DE CARLO, Sandra. Gestão ambiental nos municípios brasileiros: impasses e heterogeneidade. Tese (Doutorado) - Centro de Desenvolvimento Sustentável, Universidade de Brasília, Brasília, 2006.

FERNANDES, V.; MALHEIROS, T. F.; PHILIPPI JR., A.; SAMPAIO, C. A. C. Metodologia de avaliação estratégica de processo de gestão ambiental municipal. Revista Saude e Sociedade, v. 21, supl. 3, p. 128-143, 2012.

FERRANTE, L.; FEARNSIDE, P. M. 2019. Brazil's new president and "ruralists" threaten Amazonia's environment, traditional peoples and the global climate. Environmental Conservation, v. 46, p. 261-263.

FORTALEZA (Município). Secretaria Municipal do Urbanismo e Meio Ambiente. Fundo de Defesa do Meio Ambiente (Fundema). Disponível em: https://urbanismoemeioambiente.fortaleza.ce.gov.br/infocidade/384fundo-de-defesa-do-meio-ambiente-fundema. Acesso em: 10 ago. 2019.

GIL, A. C. Como elaborar projetos de pesquisa. 5. ed. São Paulo: Atlas, 2010.

INSTITUTO BRASILEIRO DE GEOGRAFIA E ESTATÍSTICA (IBGE). Pesquisa de Informações Básicas Municipais. Perfil dos Municípios Brasileiros: meio ambiente. 2002. Rio de Janeiro: IBGE, 2005. Disponível em: https:// biblioteca.ibge.gov.br/biblioteca-catalogo?id=26063\&view=detalhes. Acesso em: 01 jul. 2019.

Pesquisa de Informações Básicas Municipais. Perfil dos Municípios Brasileiros 2012. Rio de Janeiro: IBGE, 2013. Disponível em: http://biblioteca.ibge.gov.br/d_detalhes.php?id=264638. Acesso em: 01 jul. 2019.

Pesquisa de Informações Básicas Municipais. Perfil dos Municípios Brasileiros 2015. Rio de Janeiro: IBGE, 2015. Disponível em: https://munic.ibge.gov.br/ver_tema. php?posicao=7\&UF=27\&municipio=2709202\&periodo=2015. Acesso em: 05 fev. 2018.

Pesquisa de Informações Básicas Municipais. Perfil dos Municípios Brasileiros 2017. Rio de Janeiro: IBGE, 2017. Disponível em: http://biblioteca.ibge.gov.br/d_detalhes.php?id=264638. Acesso em: 01 jul. 2019. 
Sinopse do Censo Demográfico 2010. Disponível em: https://censo2010.ibge.gov.br/sinopse/index. php? $\mathrm{uf}=22 \&$ dados=29. Acesso em: 06 fev. 2018.

LEME, T. N. Governança Ambiental no Nível Municipal. In: MOURA, Adriana Maria Magalhães de (Org.). Governança Ambiental no Brasil: instituições e atores e políticas públicas. Brasília: Ipea, 2016.

MALHEIROS, Tadeu Fabricio; PHLIPPI JR., Arlindo; COUTINHO, Sonia Maria Viggiani. Agenda 21 nacional e indicadores de desenvolvimento sustentável: contexto brasileiro. Saúde e Sociedade, v. 17, n. 1, p. 7-20, 2008.

MINISTÉRIO DO MEIO AMBIENTE (MMA). Programa Nacional de Capacitação para Gestores Ambientais Municipais(PNC).Disponívelem:https://www.mma.gov.br/informma/item/11150-pnc.html\#hist\%C3\%B3rico. Acesso em: 22 out. 2020.

PACHECO, A. P. de C.; FIGUEIREDO NETO, F. L.; AYDOS, L. R. Gestão Ambiental Municipal no Brasil - Um Panorama entre os anos 2002 a 2013. Revista Espacios, v. 37, n. 10, 2016. Disponível: https://www.revistaespacios.com/ a16v37n10/16371004.html. Acesso em: 25 jul. 2019.

PHILLIPI JR, A. (Org.). Municípios e meio ambiente: perspectiva para a municipalização da gestão ambiental no Brasil. São Paulo: Associação Nacional de Municípios e Meio Ambiente, 1999.

PINHO, A. L.; WEINERT, W. R. Políticas Públicas Brasileiras como Tecnologias de Saúde. Guaju: Revista Brasileira de Desenvolvimento Territorial Sustentável, v. 6, n. 1, p. 147-158, jan./jun. 2020. Disponível em: http://dx.doi. org/10.5380/guaju.v6i1.72857 Acesso em: 04 set. 2020.

RECIFE (Município). Secretaria de Meio Ambiente e Sustentabilidade. Fundo Municipal de Meio Ambiente. In: RECIFE (Município). Secretaria de Meio Ambiente e Sustentabilidade. Institucional. Disponível em: http:// meioambiente.recife.pe.gov.br/fundo-municipal-de-meio-ambiente. Acesso em: 10 ago. 2019.

RICHARDSON, Roberto Jarry. Pesquisa social: métodos e técnicas. 3. ed. São Paulo: Atlas, 2011.

RODRIGUES, M. L.; FERNANDES, V. A percepção ambiental como instrumento de apoio na gestão e na formulação de políticas públicas ambientais. Saúde e Sociedade, v. 21, p. 96-110, 2012.

SCARDUA, F. Governabilidade e descentralização da gestão ambiental no Brasil. Tese (Doutorado) - Centro de Desenvolvimento Sustentável, Universidade de Brasília, Brasília, 2003.

SCARDUA, F.; BURSZTYN, M. A. A. Descentralização da política ambiental no Brasil. Sociedade e Estado, Brasília, v. 18, n. 1/2, p. 291-314, jan./dez. 2003. Disponível em: encurtador.com.br/uvEF1. Acesso em: 01 jul. 2019. 